\title{
Preparation of Macro-porous Si as a Anode Material for Li-ion Battery
}

\author{
Min Jung Kim¹, Yeon Baek Seong ${ }^{1}$, Tae Hoon Lee ${ }^{1}$, Chang Jun Park ${ }^{1}$, Jin Wook Lee, Won Young Choi ${ }^{1}$, \\ No-Kuk Park ${ }^{2}$, Tae Jin Lee ${ }^{1}$ \\ ${ }^{1}$ School of chemical engineering Yeungnam University \\ 280 Daehak-Ro, Gyeongsan, Republic of Korea \\ mj0516kim@naver.com; yeonbaek88@naver.com; 1th0830@naver.com; pcj0508@ naver.com; 0327007@naver.com; \\ cwy1990@naver.com; tjlee@ynu.ac.kr \\ ${ }^{2}$ Institute of Clean Technology Yeungnam University \\ 280 Daehak-Ro, Gyeongsan, Gyeongbuk 712-749, Republic of Korea \\ nokukpark@gmail.com
}

\section{Extended Abstract}

In lithium-ion batteries, lithium ions move between the battery's anode and cathode during charge and discharge. Carbon-based materials, like graphite and carbon micro-bead have used as anode materials for Li-ion battery. However, carbon-based anode materials have low coulombic efficiency and high irreversible capacity. In this reason, the alloys anode material mixed with the other material, such as Sn, Sb, Ge and Si etc., for enhancing the capacity of anode materials [2]. The silicon is used as a anode material for Li-ion battery to boosting the capacity of anode materials. The Silicon has the highest specific capacity (4212 mAh/g with formation of Alloy/de-alloy materials), high energy density and good safety [3]. Even though the silicon has high specific capacity, it often exhibits a swelling phenomenon during Li insertion and extraction. In this study, macro pores are existed in the silicon for prevention of the swelling phenomenon. The macroporous silicon was synthesized from TMOS(Tetra methyl ortho silicate) and PMMA(Poly methyl methacrylate). The nanosized PMMA beads used as a template for the formation of macro-pores was synthesized by the suspension polymerization method. The PMMA beads had 300nm size and it used a diffusing state in water. The TMOS was used as the precursor for the synthesis of macro-porous silica [1]. A mixture of TMOS and PMMA was thermal treated at $650{ }^{\circ} \mathrm{C}$ for $5 \mathrm{~h}$ under the air purging. Then, the macro-porous silica was mixed with aluminum powders. The aluminum powder was used for the conversion of macro-porous silica to silicon. The macro-porous silica and aluminum mixture slurry was thermal treated at $650{ }^{\circ} \mathrm{C}$ for $5 \mathrm{~h}$ under the argon purging. The macro-porous silica can be reduced to the macro-porous silicon with the reducing agents. Meanwhile, aluminum powder, used as reducing agent, is oxided for the reduction of silica. A metal oxide, like a $\mathrm{Al}_{2} \mathrm{O}_{3}$ in anode materials, can repress silicon. Therefore, the reduced macro-porous silicon sample was treated with $\mathrm{HCl}$ and $\mathrm{H}_{3} \mathrm{PO}_{4}$ in order to remove $\mathrm{Al}_{2} \mathrm{O}_{3}$. The macro pores of silicon were confirmed by $\mathrm{SEM}$ analysis. The reducing of silica was confirmed by XRD and XPS analysis.

\section{References}

[1] E. Peled, D. Golodnitsky, G. Ardel., and V. Eshkenazy., "The SEI model-application to lithium-polymer electrolyte batteries," Electrochimics Acta, vol. 40, no. 13, pp. 2197-2204, 1995.

[2] N. Nitta and G. Yushin, "High-Capacity Anode Materials for Lithium-Ion Batteries: Choice of Elements and Structures for Active Particles," Particle \& Particle Systems Characterization, vol. 31, no. 3, pp. 317-336, 2014.

[3] S. Goriparti, E. Miele, F. D. Angelis, E. D. Fabrizio, R. P. Zaccaria, C. Capiglia, "Review on recent progress of nanostructured anode materials for Li-ion batteries," J. Power Sources, vol. 257, pp. 421-443, 2004.

[4] B. M. Bang, J. I. Lee, H. J. Kim, J. P. Cho, S. J. Park, "High-Performance Macroporous Bulk Silicon Anodes Synthesized by Template-Free Chemical Etching," Adv. Energy Mater, vol. 2, pp. 878-883, 2012.

[5] C. K. Chan , H. Peng , G. Liu , K. Mcllwrath, X. F. Zhang, R. A. Huggins, and Y. Cui , "High-performance lithium battery anodes using silicon nanowires," Nat Nanotechnol, vol. 3, pp. 31-35, 2008.

[6] Y. Kubota, "Crystal and electronic structure of Li15Si4," J. Appl. Phys., vol. 102, 053704, 2007. 
[7] Balbuena Wang. (2004). Lithium-lon Batteries: Solid-Electrolyte Interphase [Online]. Available: http://www.worldscientific.com/doi/pdf/10.1142/9781860946448_fmatter.

[8] J. Li and J. R. Dahn, "An In Situ X-Ray Diffraction Study of the Reaction of Li with Crystalline Si," J. Electrochem. Soc., vol. 154, no. 3, pp. A156-A161, 2007. 